\title{
FITTER insulin technique: A psychosocial commentary
}

\author{
Sanjay Kalra, Yashdeep Gupta ${ }^{1}$, Kenneth Strauss ${ }^{2}$ \\ Department of Endocrinology, Bharti Hospital, Karnal, Haryana, 'Department of Endocrinology, All India Institutes of Medical Sciences (AIIMS), \\ New Delhi, India, ${ }^{2}$ Global Medical Director, B-D, Erembodegem, Belgium
}

\section{FITTER INSULIN TECHNIQUE: A PSYCHOSOCIAL COMMENTARY}

Insulin technique is a vital, yet oft-neglected aspect of insulin therapy, which itself is a central pillar of diabetes care. Modern guidelines recognize the psychosocial components that go into ensuring successful insulin delivery. ${ }^{[1,2]}$ Along with knowledge of anatomy and physiology, an in-depth understanding of psychology is required to minimize pathology or complications that may occur due to incorrect injection technique ${ }^{[3]}$

This editorial follows on the recently conducted Forum for Injection Technique and Therapy: Expert Recommendations (FITTER) workshop held in Rome, Italy (October 23-25, 2015) ${ }^{[3]}$ It reviews injection technique through a psychosocial prism. It also refers to the Forum for Injection Technique (FIT) India guidelines and their addenda, ${ }^{[1,2,4,5]}$ which explore issues specific to India and South Asia in greater detail.

\section{THERAPEUTIC EDUCATION}

Education related to insulin usage has a therapeutic and beneficial effect, and is mandatory. An ideal insulin prescription should not only contain the insulin preparation and explain its dose and timing of administration, but also detail the device, needle length/ gauge, site and technique of injection, and method of appropriate disposal of used sharps. Better adherence to therapy and consequently favorable clinical outcomes are obtained if such therapeutic education is delivered by formally trained health care personnel. ${ }^{[3]}$ Therapeutic patient education is a continuous, ongoing process that should be reinforced at every patient/provider point of contact, utilizing multiple means of communication, including verbal, written, and visual messaging.

\section{the Role of the health Care PROFESSIONAL (HCP)}

It is the HCP's responsibility to address the many psychological hurdles that the person with diabetes may face. Such barriers are most prominent at the time of initiation of injectable therapy. Anxieties about injection, and about insulin, need to be explored, identified, and resolved. An in-depth understanding of anatomy, physiology, and pharmacology helps in this regard. Details of psychosocial interventions that can be used to screen, diagnose, and manage such situations are described in national guidelines on the psychosocial management of diabetes and their addenda. $.6,7]$

\section{Needle Length}

Irrespective of the ethnic group being studied, skin thickness is similar is adolescents and adults. Though it may range $1.25-3.25 \mathrm{~mm}$, the average dermis is $2 \mathrm{~mm}$ thick. Thus, similar needle length $(4 \mathrm{~mm}$ pen needle and $6 \mathrm{~mm}$ syringe needle) can be advocated for use across the globe.

\section{INJECTION THROUH CLOTHING}

Injection through clothing, though very rare, is reported anecdotally from isolated pockets of South Asia, where social customs encourage modesty in attire. Such an injection technique, however, is clearly discouraged. Such practice prevents the injection site from being visualized, may insert fibers of cloth into the body, and offers no assurance of subcutaneous delivery of insulin.

\section{DIAGNOSING LIPOHYPERTHERAPY}

Current international guidelines lay out elaborate procedures for the physical examination of insulin 
injection sites. Some of the recommendations, such as "disrobing to only underclothing," may not be feasible in South Asian settings, while others ("room must be warm to prevent patient chilling") may not be required. Many health care facilities may not be able to provide a couch for the patient to lie down on, or ultrasound gel/K-Y jelly for the HCP to use as lubricant. In such cases, examination may be performed on a patient sitting, and with bare, clean hands.

\section{Needle Reuse}

An important aspect of insulin technique is the practice of needle reuse. Studies have uncovered various reasons why some patients prefer to reuse insulin needles. These include convenience, cost containment, lack of awareness of the adverse effects associated with reuse, difficulties in disposal of sharps, and concerns about the ecological imprint of excessive metal and plastic usage.

While published guidelines, both on insulin technique and on hypodermic syringe use, discourage reuse of needles National AIDS Control Organization (NACO), such reuse is commonly encountered. A recently conducted survey, presented at FITTER, revealed that some of the highest rates of reuse were encountered in China and India.

Patients who reuse needles are found to have a higher incidence of lipohypertrophy in surveys as well as trials. A recent study also found the number of uses of a needle to correlate with the risk of lipohypertrophy.

Reuse is also associated with greater injection pain, perhaps due to the dulling of the needle tip and inflammatory changes (redness of skin) at the injection site. Other researchers, however, report that using pen needles up to 4-5 times does not cause needle tip deformity and does not increase pain intensity.

While reuse should certainly not be encouraged, it must be realized that many patients may be compelled to, or even choose to, reuse their needles. In such a situation, the HCP's role must be clarified [Table 1]. The astute professional must discuss the issue of needle reuse (and needle recapping) with the patient in a spirit of shared decision-making. The pros and cons of this practice must be evaluated for each individual clinical situation. A biopsychosocial model utilizing psychological and social variables along with biomedical parameters may be used to inform decision-making. For example, a patient who cannot afford to pay for needles or dispose of them easily may wish to reuse them, while one who fears self-induced

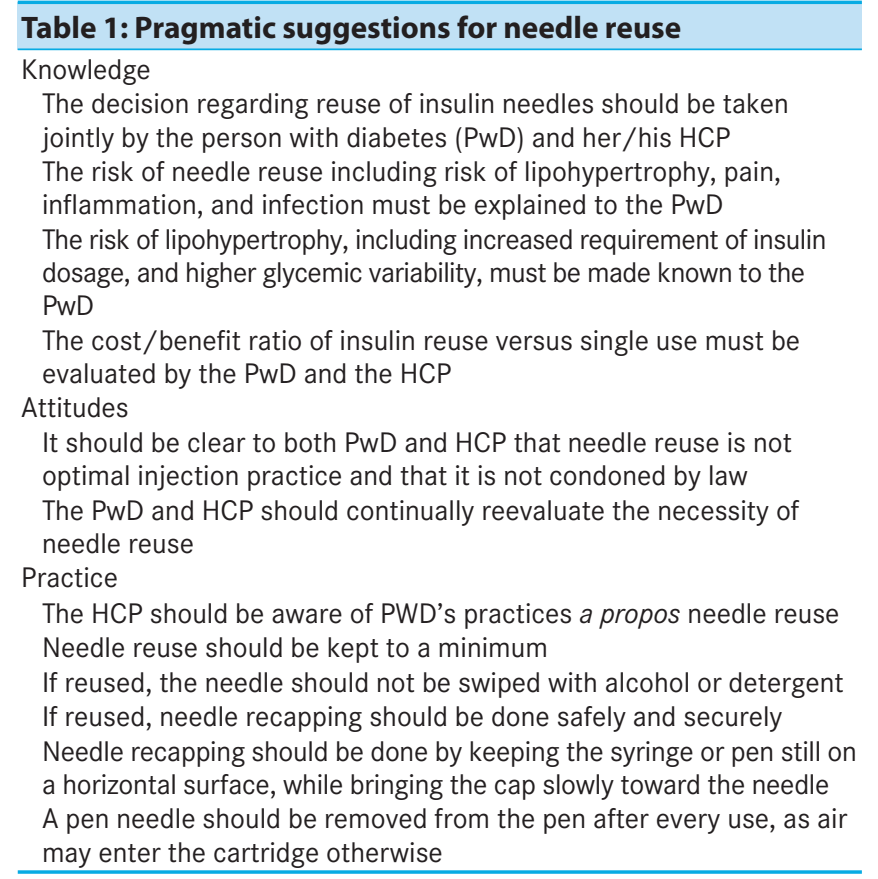

needlestick injury or is at increased risk of sharps injury because of impaired locomotor skills may choose to discard needles after single use.

Needle manufacturers discourage needle reuse, citing legal requirements to guarantee the sterility of their products, which is not possible in reused devices. Official labelling on needles requires both single use and sterility symbols, and manufacturers' recommendations have to be concordant with these labels. If diabetes care professionals proactively advise against the official labelling, they assume the responsibility of going against legal rules.

\section{SUMMARY}

Newer insulin techniques provide a comprehensive overview of the rationale and the method of optimal injection technique, suited for global audiences. Certain issues, including those related to the role of the HCP, needle length, examination through clothing, diagnosis of lipohypertrophy, and needle reuse, are discussed in this editorial. This commentary should strengthen the FITTER and FIT. 2.0 India guidelines by adding weight and pragmatism to their recommendations.

\section{REFERENCES}

1. Kalra S, Balhara YP, Baruah MP, Chadha M, Chandalia HB, Chowdhury S, et al. Forum for injection techniques, India: The first Indian recommendations for best practice in insulin injection technique. Indian J Endocr Metab 2012;16:876-85. 
2. Tandon N, Kalra S, Balhara YS, Baruah MP, Chadha M, Chandalia HB, et al. Forum for Injection Technique (FIT), India: The Indian recommendations 2.0, for best practice in Insulin Injection Technique, 2015. Indian J Endocrinol Metab 2015;19:317-31.

3. Forum for Injection Technique and Therapy Expert Recommendations. Available from: http://www.fitter4diabetes. com/. [Last accessed on 2015 Oct 26].

4. Kalra S, Balhara YP, Baruah MP, Chadha M, Chandalia HB, Chowdhury S, et al. Addendum 2: Forum for Injection Technique, India. Indian J Endocrinol Metab 2014;18:800-3.

5. Kalra S, Balhara YS, Baruah MP, Chadha M, Chandalia HB, Chowdhury $\mathrm{S}$, et al. Addendum: First injection technique

\begin{tabular}{|l|l|}
\hline \multicolumn{2}{|c|}{ Access this article online } \\
\hline Quick Response Code: & Website: \\
\hline & www.josh.net \\
\hline & \\
\hline
\end{tabular}

recommendations for patients with diabetes, Forum for Injection Techniques India. Indian J Endocrinol Metab 2013;17:1005-8.

6. Kalra S, Sridhar GR, Balhara YS, Sahay RK, Bantwal G, Baruah MP, et al. National recommendations: Psychosocial management of diabetes in India. Indian J Endocrinol Metab 2013;17:376-95.

7. Kalra S, Baruah MP, Ranabir S, Singh NB, Choudhury AB, Sutradhar S, et al. Guidelines for ethno-centric psychosocial management of diabetes mellitus in India: The north east consensus group statement. J Soc Health Diabetes 2013;1:9-14.

This is an open access article distributed under the terms of the Creative Commons Attribution-NonCommercial-ShareAlike 3.0 License, which allows others to remix, tweak, and build upon the work non-commercially, as long as the author is credited and the new creations are licensed under the identical terms.

How to cite this article: Kalra S, Gupta Y, Strauss K. FITTER insulin technique: A psychosocial commentary. J Soc Health Diabetes 2016;4:3-5. 